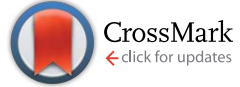

Cite this: RSC Adv., 2017, 7, 11987

Received 2nd February 2017

Accepted 14th February 2017

DOI: $10.1039 / c 7 r a 01363 a$

rsc.li/rsc-advances

\section{Tailored performance of layered transition metal dichalcogenides via integration with low dimensional nanostructures}

\author{
De-Sheng Liu, ${ }^{\mathrm{a}}$ Jiang Wu, ${ }^{\mathrm{b}}$ Yanan Wang, ${ }^{\mathrm{c}}$ Haining Ji, ${ }^{\text {a }}$ Lei Gao, ${ }^{\mathrm{a}}$ Xin Tong, ${ }^{\mathrm{c}}$ \\ Muhammad Usman, ${ }^{c}$ Peng $\mathrm{Yu}^{* c}$ and Zhiming Wang*c
}

Transition metal dichalcogenides (TMDs) with a unique sandwich structure have attracted tremendous attention in recent years due to their distinctive electrical and optical properties. The performance of TMDs can be tailored by integration with low dimensional nanostructures which possess quantum size effects and large specific surface areas. In this review, we give a brief description of integrated structures, their synthesis methods, and highlight the applications in hydrogen production, lithium batteries, sensors and detectors.

\section{Introduction}

Since the advent of graphene in 2004, two-dimensional (2D) materials with large specific surface areas and excellent electronic and optical properties have attracted significant attention in various fields such as energy storage, sensing, electronic and optoelectronic devices. ${ }^{1-7}$ Among them, transition metal dichalcogenides (TMDs, e.g. $\mathrm{MoS}_{2}, \mathrm{MoSe}_{2}, \mathrm{WS}_{2}, \mathrm{WSe}$ ) are gradually becoming hotspots of research due to their novel structure and remarkable properties. ${ }^{\mathbf{8} 9}$ These materials present a $\mathbf{M X}_{2}$ stoichiometry, where $\mathrm{M}$ is a transition metal and $\mathrm{X}$ is a chalcogenide. ${ }^{\mathbf{1 0}}$ They possess a unique $2 \mathrm{D} \mathrm{X}-\mathrm{M}-\mathrm{X}$ structure, in which the monolayer consists of transition metal atoms and chalcogen atoms interacting with strong covalent bonds, while adjacent TMDs layers are formed by weak van der Waals forces. ${ }^{11,12}$ TMDs with semiconducting properties have a tuneable bandgap around 1-2 eV, and the bandgap becomes direct when the thickness of crystals decreases to a single layer, indicating that TMDs are promising materials in optoelectronic applications. ${ }^{13-15}$

TMDs-based heterostructures with outstanding properties and novel phenomena have been widely investigated. ${ }^{16,17}$ These heterostructures not only inherit the properties of individual components, but also present innovative properties, such as Moiré pattern-induced wave function localization in $\mathrm{MoS}_{2} / \mathrm{MoSe}_{2}$ heterostructures and larger on/off ratio in graphene/ $\mathrm{MoS}_{2}$ heterostructures-based transistor. ${ }^{18-20}$ With the development of

${ }^{a}$ State Key Laboratory of Electronic Thin Film and Integrated Devices, University of Electronic Science and Technology of China, Chengdu 610054, P. R. China. E-mail: hainingji@uestc.edu.cn

${ }^{b}$ Department of Electronic and Electrical Engineering, University College London, Torrington Place, London WC1E 7JE, UK

'Institute of Fundamental and Frontier Science, University of Electronic Science and Technology of China, Chengdu 610054, P. R. China. E-mail: azarisyu@gmail.com; Zhimingwang@uestc.edu.cn these heterostructures, new properties can be designed and tailored beyond the capability of conventional TMDs. ${ }^{21}$ These TMDs-based heterostructures can be integrated via various routes, including 0D quantum dots (QDs) and 1D nanotubes (NTs), ${ }^{22}$ or 0D QDs and 2D nanosheets (NSs), ${ }^{23}$ or 1D nanorods (NRs) and 2D NSs as well. ${ }^{24}$ Here, we focus on heterostructures composed of $2 \mathrm{D}$ TMD NSs and low dimensional nanostructures (LDNs).

LDNs such as nanodots (NDs), nanoparticles (NPs), nanowires (NWs) and nanobelts (NBs) with quantum size effects and large specific surface areas usually exhibit novel properties differ from their bulks. ${ }^{25-27}$ For instance, $\mathrm{Nb}_{2} \mathrm{O}_{5}$ shows an increased band gap from $3.4 \mathrm{eV}$ to $4.2 \mathrm{eV}$ when its particle size decreases to nanoscale. ${ }^{28}$ Owing to tuneable optical properties and the effect of surface chemistry, some materials in low dimension show enhanced photoluminescence (PL), high sensitivity to detect gas or biological molecules, absorptivity of dye molecules, and improved charge transport ability. ${ }^{29-32}$ Therefore, a method of fabricating TMD-based heterostructures via integrating with LDNs is a potential approach to enhance performance in corresponding devices. ${ }^{21,33,34}$

Although many comprehensive reviews regarding TMDs have been reported, ${ }^{\mathbf{1 6 , 1 7 , 3 5 - 3 8}}$ there is still no systematic review with respect to LDNs/TMDs integration. In this review, we began with a brief description of integrated structures. We then outlined the synthesis methods of TMDs NSs and provided two main routes: self-assembly and hydrothermal/solvothermal to prepare LDNs/TMDs nanostructures. Subsequently, we highlight their applications and device performance. In the last part, a short summary is given.

\section{Integrated structures}

\subsection{Low dimensional nanostructures}

When the material size shrinks into nanoscale, the number of atoms or molecules forming the material becomes an 
influential role to the physicochemical properties and reactivity. ${ }^{39}$ In order to simplify the size and dimensional effects, it is preferable to classify the materials according to the number of dimension with expansion freedom (not restricted in nanosize). For example, NDs and NPs, of which all dimensions are in the range of a few nanometres, belong to $0 \mathrm{D}$ category; and 3D materials usually refer to bulk materials. For the same material, the allotropes usually exhibit dimension-dependent distinctive properties. One of the typical instances is the allotropes of carbon materials. For a given carbon concentration, 1D multiwall carbon nanotubes (MWNTs) has higher photomechanical stress response and energy conversion efficiency than 2D single layer graphene and 3D graphite under illumination of nearinfrared (NIR) light. ${ }^{40}$ In another case, silicon materials with different dimension show different optical properties. While the bulk silicon does not emit visible light due to the indirect bandgap, the low dimensional $\mathrm{Si}$ nanostructures with the quantum-confinement effect are able to emit visible light..41,42 Besides, Si NWs structures have a small reflection in a wide spectrum range compared to $2 \mathrm{D}$ thin films, which improves the optical absorption in the high-frequency regime. ${ }^{43}$ In some metal materials, such as $\mathrm{Au}$ and $\mathrm{Ag}$, when the dimension of metal crystals decreases to nanoscale, these nanostructures arrays demonstrate surface plasmon resonance phenomenon under light illumination. ${ }^{\mathbf{4 4}, 45}$ The collective motion of conduction band electrons related to fixed positive ions give rise to a plasmon oscillation in a metal under incident light. ${ }^{46}$ This unique optical property provides some inspirations for applications such as biosensors and solar cells. ${ }^{47}$

In LDNs materials, a small change of size will alter its optical properties due to quantum confinement effect. ${ }^{48-50}$ For instance, Xue et al. demonstrated that the $\mathrm{TiO}_{2}$ NPs with a size varied from $6.8 \mathrm{~nm}$ to $14.2 \mathrm{~nm}$ have a large difference on Raman intensity, which can be attributed to the charge-transfer resonance between the $\mathrm{TiO}_{2}$ and the adsorbed molecules. ${ }^{51}$ Similarly, owing to the size effect, an absorption peak redshifts of $\mathrm{Au}$ NPs is observed when the particle diameter increased from $20 \mathrm{~nm}$ to $100 \mathrm{~nm} .^{52}$ Therefore, the metal NPs with localized surface plasmon resonances can be employed to develop refractive index sensors through combining with microfiber. ${ }^{53}$ In addition, some LDNs materials also exhibit distinct chemical, electrical or biological properties due to the size effect. ${ }^{54-56}$ For example, CdSe QDs employed for biological application, the smaller sized QDs have a greater improvement in enzymatic activity compared with the larger QDs. ${ }^{57}$ In general, these materials in low dimension with unique characteristics are applied in a range of fields such as catalysis, sensing, electronic and optoelectronic. ${ }^{\mathbf{5 8 , 5 9}}$

\subsection{Electronic and optical properties of 2D TMDs}

TMDs materials are comprised of a transition metal element of groups IV - X and a chalcogen element such as sulfur (S) and selenium (Se).$^{60}$ Bulk TMDs exhibit a wide variety of polymorphs as compared to other $2 \mathrm{D}$ counterparts, and they cover a wide spectrum of properties such as semiconductivity, half-metallic magnetism and superconductivity. ${ }^{61}$ When the d-orbitals of transition metal are partially occupied, TMDs display metallic conductivity properties, whereas these materials are semiconductors when the orbitals are fully occupied. ${ }^{10}$ In bulk phase of TMDs, there are three possible stacking structures: $1 \mathrm{~T}, 2 \mathrm{H}$ and $3 \mathrm{R}$ with tetragonal symmetry, hexagonal closed packing and rhombohedral symmetry, respectively. ${ }^{9}$ However, monolayer TMDs are demonstrated to possess two polytypes, metallic $1 \mathrm{~T}$ phase and semiconducting $2 \mathrm{H}$ phase, and the stacking structures are shown in Fig. $1 .^{62}$ It has been demonstrated that the $2 \mathrm{H}$ stacking structure can be converted into $1 \mathrm{~T}$ stacking structure by Li intercalation or plasmonic hot electron induced structure phase transition., ${ }^{\mathbf{5} 63}$ The metallic $1 \mathrm{~T} \mathrm{MoS}_{2}$ employed as electrode materials exhibits outstanding capacitive behaviour in both aqueous and organic electrolytes due to their intrinsic hydrophilicity and high electrical conductivity. ${ }^{\mathbf{6 4}}$

Semiconducting TMDs such as $\mathrm{MoS}_{2}$ and $\mathrm{WS}_{2}$ with a tuneable band gap promote their applications in photoelectric field. ${ }^{\mathbf{9}, \mathbf{6 5 , 6 6}}$ With decreasing layer number, the band gap present an increasing trend, and the indirect band gap of bulk TMDs gradually shift to be direct when reduced to single layer. ${ }^{67}$ Fig. 2 shows a band structure of bulk and monolayer $\mathrm{MoS}_{2}$ calculated from first principles. ${ }^{68}$ At the $\Gamma$-point, bulk $\mathrm{MoS}_{2}$ has an indirect band gap of $1.2 \mathrm{eV}$, which can be transferred to a direct band gap of $1.9 \mathrm{eV}$ in monolayer form. This phenomenon can be explained by quantum confinement effect. ${ }^{14,69}$ Owing to the direct band gap, a strong PL is observed in monolayer $\mathrm{MoS}_{2}$, and the PL quantum yield (QY) has a $10^{4}$ fold enhancement compared with their bulk crystal. ${ }^{70}$ Moreover, the PL of monolayer $\mathrm{MoS}_{2}$ can be effectively improved via an air-stable, solution-based chemical treatment and the consequent QY is more than 95\%. ${ }^{71}$ Therefore, single layer semiconducting TMDs with direct band gap indicates that they are promising candidates in optoelectronic applications. ${ }^{72}$

\subsection{LDNs/TMDs heterostructures}

The integration of materials in different dimensionalities is able to combine the inherent advantages and mitigate the genetic disadvantages in terms of fundamental properties. ${ }^{73}$ Noble metals, metal oxides, graphite derivatives crystals with sizes in nanoscale such as Au NPs and carbon NTs (CNTs) can be integrated with 2D TMDs NSs. The as-prepared heterostructures present an obviously enhanced performance in
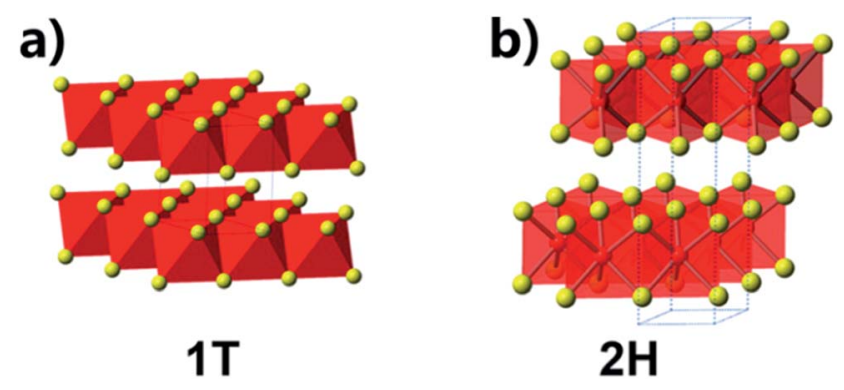

Fig. 1 Crystal structures of (a) $1 \mathrm{~T}$ and (b) $2 \mathrm{H}$ crystal structures of the TMDs. Adapted with permission from ref. 6. Copyright 2013 American Chemical Society. 


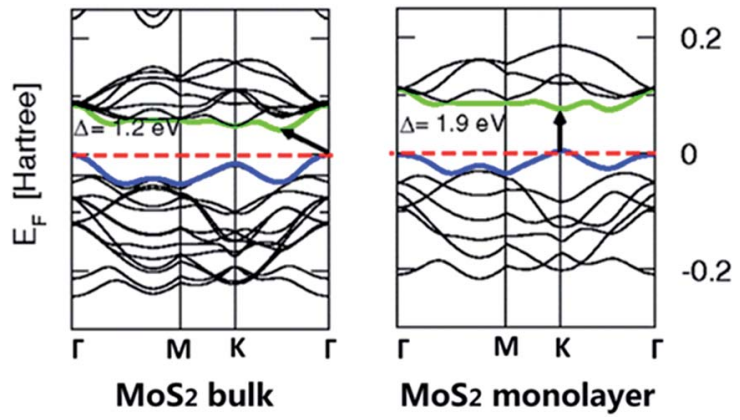

Fig. 2 Band structures of bulk $\mathrm{MoS}_{2}$ and its monolayer. The arrows indicate the smallest value of the band gap (direct or indirect) for a given system. The top of valence band (blue) and bottom of conduction band (green) are highlighted. Adapted with permission from ref. 68. Copyright 2011 by the American Physical Society.

electrical and optical application..$^{74-77}$ For instance, Zhou et al. prepared $\mathrm{TiO}_{2}$ NBs@MoS 2 NSs heterostructure via a hydrothermal reaction, and the heterostructure exhibits highly photocatalytic hydrogen production. ${ }^{78}$ Herein, the synergistic effect of $\mathrm{TiO}_{2}$ and $\mathrm{MoS}_{2}$ resulting in the heterostructure provides efficient charge separation to suppress the electron-hole recombination, and further display an improved photocatalytic activity. In another case, Zhang et al. reported a hydrothermal method to fabricate a $\mathrm{ZnO} \mathrm{NRs} / \mathrm{MoS}_{2}$ NSs heterostructure without a catalyst. ${ }^{79}$ Due to the light antennae effect of ZnO NRs, enhanced Raman and PL emission are observed in this type of heterostructure.

According to the dimension of nanostructures, these heterostructures can be divided into $0 \mathrm{D} / 2 \mathrm{D}$ and $1 \mathrm{D} / 2 \mathrm{D}$, as shown in Fig. 3. Generally, OD nanostructures usually tiled on TMDs NSs, and 1D nanostructure usually served as an axis for TMDs NSs, which were loaded on their surface in form of $1 \mathrm{D} / 2 \mathrm{D} .^{21,80-82}$ Every individual structure in these heterostructures plays an important role and contributes to tailored performance of the whole system. Layered TMDs have several crystal phases with different lattice structures and electronic character such as $1 \mathrm{~T}$ and $2 \mathrm{H}$, although integrated with the same LDNs, these heterostructures exhibit distinct performance. ${ }^{83,84}$ Bai et al. demonstrated that $\mathrm{TiO}_{2}-\mathrm{MoS}_{2}(1 \mathrm{~T})$ hybrid structure exhibited excellent performance as a co-catalyst to product hydrogen, which is in sharp contrast to $\mathrm{TiO}_{2}-\mathrm{MoS}_{2}(2 \mathrm{H}){ }^{85}$ This can be attributed to the active sites on the $1 \mathrm{~T}-\mathrm{MoS}_{2}$ basal plane, which gives rise to a high charge diffusion rate and reduces the probability of charge recombination when integrated with $\mathrm{TiO}_{2}$. On the contrary, $2 \mathrm{H}-\mathrm{MoS}_{2}$ does not provide reaction sites and may block the active sites on the $\mathrm{TiO}_{2}$ nanocrystals surface. In addition, the layer numbers can affect the electrical and optical properties of TMDs. For example, monolayer $\mathrm{MoS}_{2}$ has a large enhancement of the luminescence compared with the bulk material. ${ }^{13}$ Therefore, layer number and crystal phase of TMDs are indispensable considerations when integrated with LDNs. Besides, the morphology and distribution of LDNs have impact on the system performance. ${ }^{86,87}$ For instance, Wang et al. prepared various morphologies of spherical, triangle, clover-like and flower-like AuNPs (Fig. 4) by changing the ratio of $\mathrm{MoS}_{2}$ and

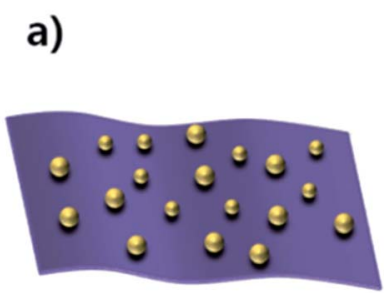

b)
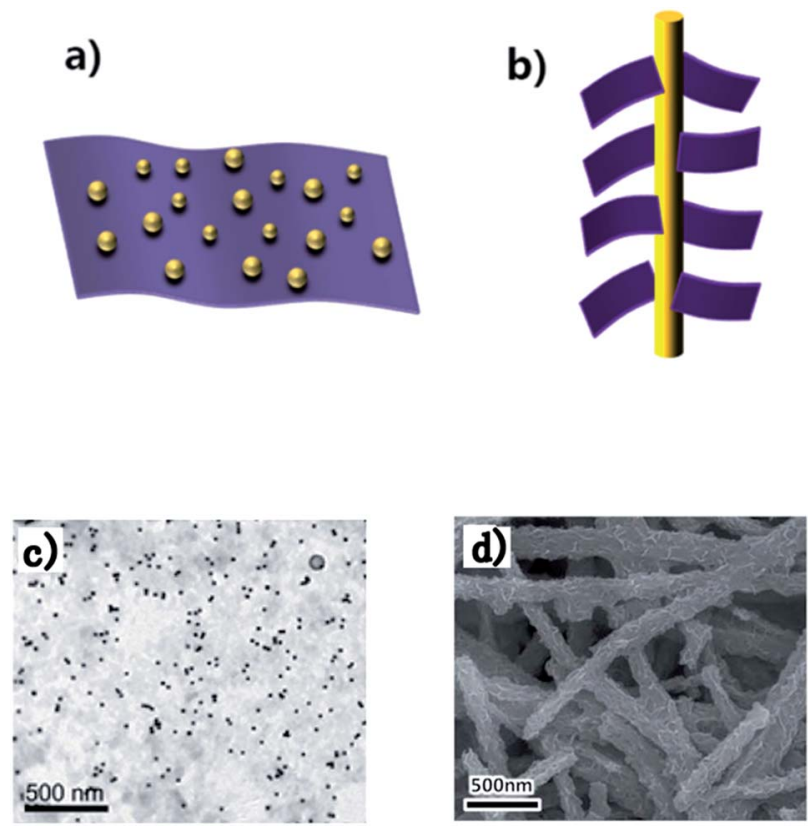

Fig. 3 Schematic of integrated heterostructure (a) OD/2D and (b) 1D/ 2D. SEM images of (c) OD Au NPs/2D $\mathrm{MoS}_{2} \mathrm{NSs}$ and (d) $1 \mathrm{D} \mathrm{TiO}_{2} \mathrm{NBs} / 2 \mathrm{D}$ $\mathrm{MoSe}_{2}$ NSs. Adapted from ref. 75 and 89 with permission of The Royal Society of Chemistry.

thionine (Thi), and demonstrated the clover-like Au NP/Thi$\mathrm{MoS}_{2}$ nanocomposites-based electrochemical immunosensor exhibit an excellent selectivity, which can detect carcinoembryonic antigen (CEA) as low as $0.52 \mathrm{pg} \mathrm{mL}^{-1}$. $^{88}$

\section{Synthesis methods}

Preparation of high quality TMDs NSs is an important process in their heterostructures fabrication. Both physical and chemical methods can be considered to obtain layered TMDs, such as exfoliation and chemical vapor deposition (CVD) ${ }^{21,90-94}$ For the synthesis of integrated nanostructures, different approaches have already been developed, as concluded in Table 1, which can be classified into two main methods: self-assembly and hydrothermal/solvothermal.

\subsection{Layer TMDs}

To date, exfoliation of layered solid and CVD growth method are mainstream strategies to obtain layered TMDs. Typically, mechanical exfoliation use micromechanical force to separate bulk materials and obtain single or few layers NSs, but the yield is relatively low and the size is quite small. ${ }^{60}$ In comparison, chemical exfoliation can conquer these problems and obtain large-scale TMDs NSs. Zheng et al. used metal naphthalenide as intercalating agents to exfoliate metal chalcogenides and obtained high quality sheets with large size up to $400 \mu \mathrm{m}^{2}{ }^{25}$ The size distribution of the flakes is much better than the sheets obtained by using organolithium salts, and the prepared TMDs sheets could be directly jet-printed on substrate. Shear exfoliation can also prepare TMDs NSs by separating bulk materials. 

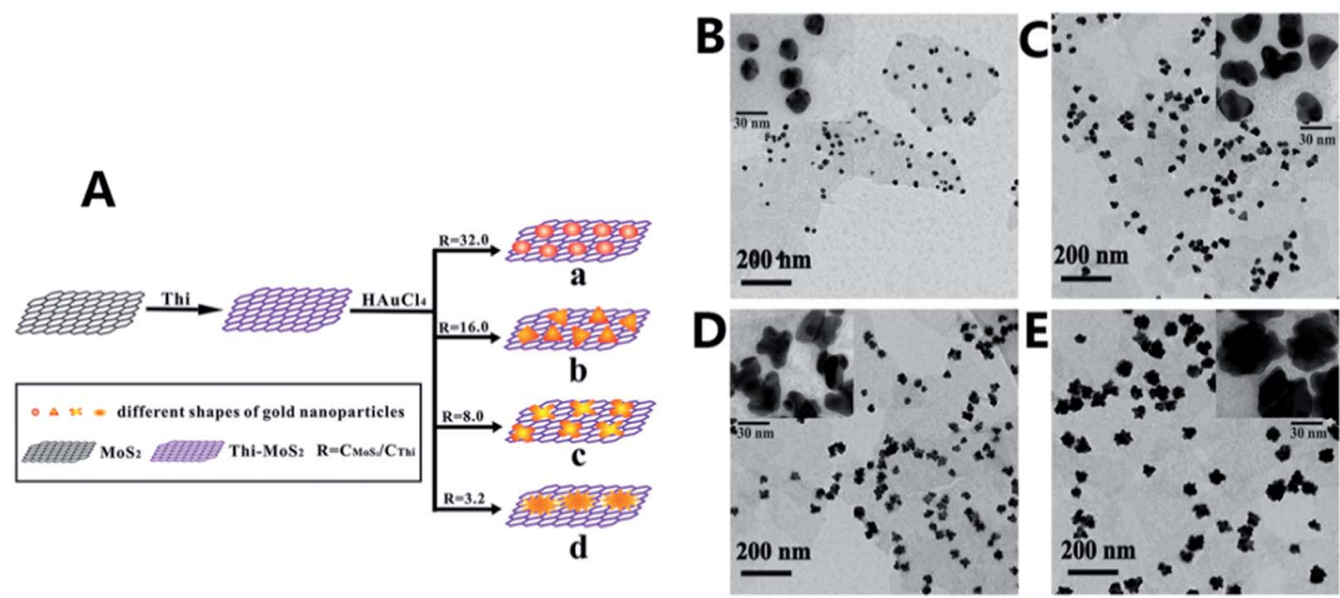

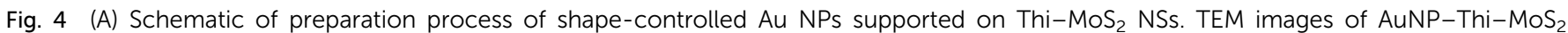
nanocomposites with (B) spherical, (C) triangle, (D) clover-like and (E) flower-like AuNPs. Adapted from ref. 88 with permission of The Royal Society of Chemistry.

Table 1 Summary of synthesis methods for integrated nanostructure

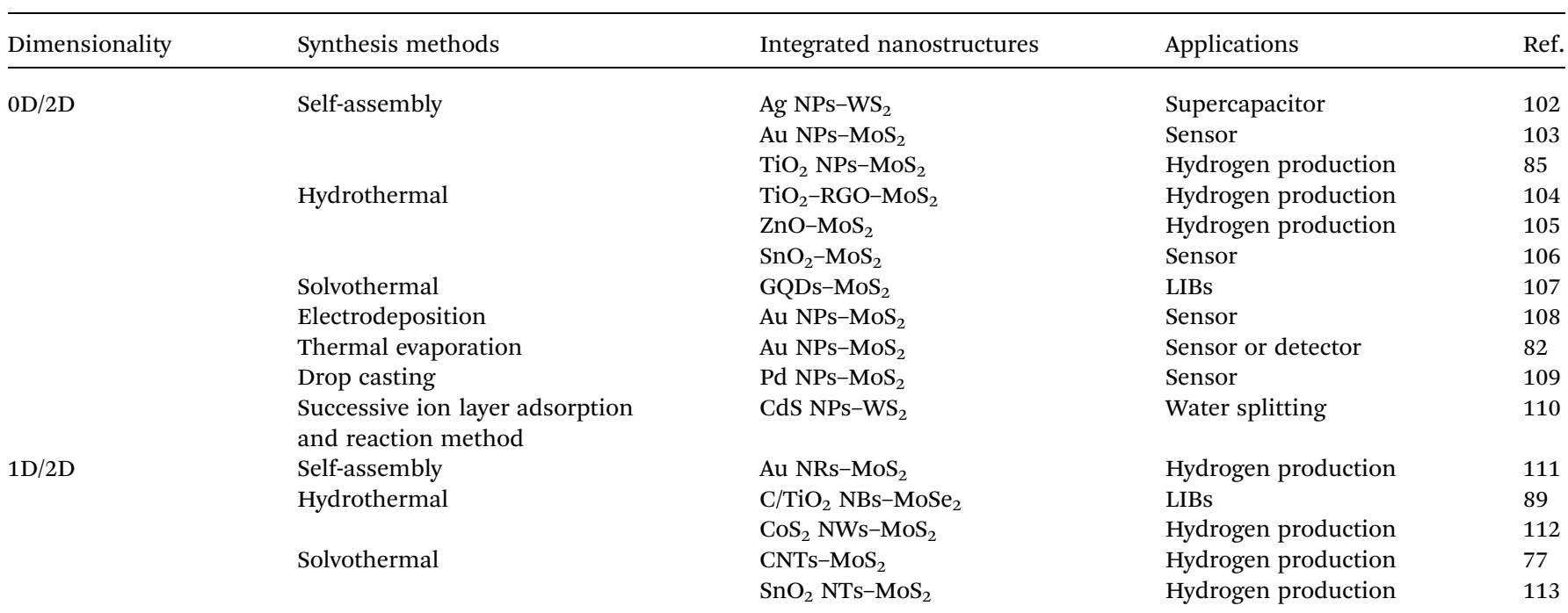

Varrla et al. demonstrated the processing parameters for specific NSs concentration, length, and thickness and obtained large-scale shear-exfoliation of $\mathrm{MoS}_{2}$ NSs (in the range $\sim 40-$ $220 \mathrm{~nm}$ for length and $\sim 2-12$ layers for thickness) in aqueous surfactant solution by using a kitchen blender. ${ }^{96} \mathrm{CVD}$ is a typical method to prepare high-quality TMDs layers with controllable thickness and scalable size. ${ }^{90}$ Lee et al. has utilized CVD approach to synthesis large-area $\mathrm{MoS}_{2}$ NSs with six-fold symmetry hexagonal lattice and high crystallinity on $\mathrm{SiO}_{2} / \mathrm{Si}$ substrates. ${ }^{97}$ In addition to preparing layered TMDs with certain thickness, CVD growth method provide a facile way to directly grow layered heterostructures, which eliminates interfacial contamination interfused during synthesis processes. ${ }^{98}$ Moreover, wet chemical approach is another available method to prepared layered TMDs, which can be directly obtained in solution with a high yield. ${ }^{99}$ However, improved purity and controllability over nanostructures are primary challenges because of infancy. ${ }^{\mathbf{1 0 0 , 1 0 1}}$ In general, chemical exfoliation is desirable method for mass production of TMDs NSs, because other methods usually have more or less limitations to some extent, such as low efficiency, long and complex process, requirement for expensive systems and severe synthetic conditions. $^{114}$

\subsection{LDNs/TMDs nanostructures}

3.2.1 Self-assembly. Self-assembly approach offers a route for assembling various functional components and preserve lattice integrity. ${ }^{115}$ These discrete components spontaneously integrate to be a complete heterostructure via directly and/or indirectly specific interactions. ${ }^{\mathbf{1 1 6}}$ The main synthesis process is immersing as-prepared NSs into nanostructure precursor solution and using available auxiliary technique to assist LDNs to be decorated on TMDs NSs. For instance, Shi and coworker 
reported a simple method to decorate Au NPs on chemical exfoliation $\mathrm{MoS}_{2}$ NSs and CVD-prepared $\mathrm{MoS}_{2}$ NSs. ${ }^{87}$ The CVD$\mathrm{MoS}_{2}$ NSs on sapphire substrates are directly immersed in $\mathrm{AuCl}_{3}$ for 20 seconds, while the chemical exfoliation NSs need to disperse on water surface and then added several drops of $\mathrm{AuCl}_{3}$. Au ions in the solution are reduced, leading to the anchoring of $\mathrm{Au}$ NPs on $\mathrm{MoS}_{2}$ surface due to active nucleation sites of NSs.

Self-assembly is also available for metal oxide/TMDs heterostructure synthesis. Bai et al. prepared a $\mathrm{TiO}_{2}-\mathrm{MoS}_{2}$ (1T) hybrid structure via sonication. ${ }^{85}$ The typical procedure is mixing the dispersion of $\mathrm{MoS}_{2}$ NSs with aqueous dispersion of $\mathrm{TiO}_{2}$ nanocrystals and then sonicated for $3 \mathrm{~min}$. In another case, Sun et al. prepared a p-type semiconductor of $\mathrm{Cu}_{2} \mathrm{O}$ decorated with $\mathrm{MoS}_{2}$ NSs by using hexadecyl trimethylammonium bromide (CTAB) as the surfactant to control the morphology. ${ }^{117}$ Asprepared nanocomposite exhibits efficient solar hydrogen production under visible light.

Size distribution, morphology and density of metal NPs can be tuned by changing the defects density in TMDs layers. ${ }^{\mathbf{8 7 , 1 1 8}} \mathrm{Lu}$ et al. reported that a focused laser beam can achieve active surface domains in $\mathrm{MoS}_{2}$ film, and the size of as-prepared $\mathrm{Au}$ NPs are controllable, which were preferentially decorated onto the modified regions. ${ }^{\mathbf{1 0 3}}$ The rough surface of laser-pruned $\mathrm{MoS}_{2}$ could trap the precursor and provide initial nucleation sites for Au NP growth.

3.2.2 Hydrothermal/solvothermal. Hydrothermal and solvothermal methods are widely used to prepare the composite structures. The reaction is usually conducted in a heated solution beyond ambient temperature and pressure. ${ }^{119}$ Zhang et al. demonstrated a facile one-step hydrothermal synthesis to prepare $\mathrm{Au}$ NPs/ $\mathrm{MoS}_{2} \cdot{ }^{120}$ In an aqueous solution, hydrazine act as strong reductant reduced $\mathrm{HAuCl}_{4}$ to Au NPs attached onto $\mathrm{MoS}_{2}$ NSs with the S-Au bond. Su et al. reported a microwaveassisted hydrothermal method to prepare $\mathrm{Au} \mathrm{NPs} / \mathrm{MoS}_{2}$ in a microwave reactor with a heated condition. ${ }^{121}$ In a typical synthesis process, $\mathrm{MoS}_{2}$ NSs solution were first mixed with sodium citrate tribasic dehydrate, Tween and $\mathrm{HAuCl}_{4} \cdot 3 \mathrm{H}_{2} \mathrm{O}$, and then heated to $60{ }^{\circ} \mathrm{C}$ for $5 \mathrm{~min}$ in a microwave reactor. Finally, the target product of Au NPs/MoS 2 can be obtained with purification via a centrifugation step.

CNTs/TMDs heterostructure is widely studied in recent years due to their remarkable catalytic activity. ${ }^{77,122,123}$ Using in situ solid and hydrothermal reactions, Zhang et al. prepared $\mathrm{Mo}_{2} \mathrm{C}$ embedded N-doped $\mathrm{CNTs} / \mathrm{MoS}_{2}$ nanostructure. ${ }^{124}$ In $\mathrm{MoO}_{2} /$ $\mathrm{Mo}_{2} \mathrm{C}-\mathrm{NCNTs}$ aqueous solution, $\mathrm{O}^{2-}$ ions are replaced with $\mathrm{S}^{2-}$ ions which resulted in the transformation of $\mathrm{MoO}_{2}$ to $\mathrm{MoS}_{2}$. Metal oxide/TMDs nanocomposites can be prepared through this method as well. Li et al. demonstrated that with the assistance of glucose, $\mathrm{TiO}_{2}$ NWs can act as a backbone for the nucleation and growth of $\mathrm{MoS}_{2}$ NSs. ${ }^{125}$ As a binder, glucose suppressed the growth and stack of layered $\mathrm{MoS}_{2}$, facilitating the growth of $\mathrm{MoS}_{2}$ NSs with smaller sizes on the $\mathrm{TiO}_{2}$ NWs surface. ${ }^{\mathbf{1 2 5 , 1 2 6}}$ Liu et al. prepared a $\mathrm{SnO}_{2}$ @ $\mathrm{MoSe}_{2}$ nanostructure through facile electrospinning technique and solvothermal method. ${ }^{127} \mathrm{SnO}_{2}$ NFs are first obtained via a simple electrospinning method, then mixed with Se solution and dispersed in
$\mathrm{Na}_{2} \mathrm{Mo}_{4}$ solution, which is subsequently heated to $180{ }^{\circ} \mathrm{C}$ and maintained for $12 \mathrm{~h}$. The black precipitates of $\mathrm{SnO}_{2} @ \mathrm{MoSe}_{2}$ after natural cooling exhibit excellent electrochemical activity as catalyst.

Wu et al. reported a green technique to prepare the $\mathrm{WS}_{2}$ and $\mathrm{MoS}_{2}$ QDs/NSs composites by sonication and solvothermal treatment. ${ }^{114}$ Typically, bulk $\mathrm{MoS}_{2} / \mathrm{WS}_{2}$ powders were sonicated in $\mathrm{N}$-dimethylformamide for $3 \mathrm{~h}$, and then stirred the top $2 / 3$ of the dispersion for $6 \mathrm{~h}$ at $140{ }^{\circ} \mathrm{C}$. After settled the suspensions for several hours, the light yellow supernatant of $\mathrm{MoS}_{2} / \mathrm{WS}_{2}$ QDS and the centrifugate of composite of $\mathrm{MoS}_{2} / \mathrm{WS}_{2}$ QDs and NSs composites were separated. In addition, Li et al. prepared a new type of 1D/2D heterostructures: GeS NWs are grown as seeds followed by GeS NSs epitaxially growing at the pre-grown NWs. ${ }^{73}$ The pre-grown NWs exposing to air caused a mild degree of oxidation at the NW surface, which could prompt the nucleation of the NSs. This strategy opens a novel avenue to synthesis NWs/NSs heterostructures.

\section{Applications}

\subsection{Hydrogen production}

Hydrogen is regarded as a potential fuel in the future to address the environmental crises and energy shortage issues. ${ }^{\mathbf{1 2 8 , 1 2 9}}$ Utilizing electricity to split water is a green and effective approach to produce hydrogen. In general, it can be divided into two strategies: electrocatalytic and photoelectrocatalytic. ${ }^{\mathbf{1 3 0 , 1 3 1}}$ Noble metals such as $\mathrm{Pt}, \mathrm{Pd}, \mathrm{Ru}$ and $\mathrm{Au}$ are widely known as effective electrochemical catalysts due to their excellent catalytic activity. ${ }^{132} \mathrm{Pt}$ and its alloys have usually been the first choice of catalysts, however, scarcity and high cost severely hinder its practical application. ${ }^{\mathbf{1 3 3 , 1 3 4}}$ TMDs are regarded as ideal candidates to replace Pt due to high chemical stability and excellent electrocatalytic properties. ${ }^{135}$ For instance, nanoscale $\mathrm{MoS}_{2}$ exhibits a good reduction capacity for protons due to the quantum confinement effect, and the marginal edges served as active sites can promote the decomposition of water. ${ }^{76}$ Xie et al. demonstrated defect-rich $\mathrm{MoS}_{2}$ NSs could present excellent hydrogen evolution reaction (HER) activity with a low onset overpotential of $120 \mathrm{mV}$ and small Tafel slope of $50 \mathrm{mV} \mathrm{dec}{ }^{-1} .^{\mathbf{1 3 6}}$ However, low conductivity of TMDs largely limited the charge transfer rate and affected the total efficiency. ${ }^{\mathbf{1 3 7}}$ An efficient way to address this issue is integrating TMDs nanostructures with conductive substrates, ${ }^{\mathbf{1 2 4}}$ such as graphene, carbon NTs or carbon NFs. Guo et al. prepared a N-doped CNFs/defect and Srich $\mathrm{MoS}_{2}$ heterostructure for high efficiency HER with a small overpotential of $135 \mathrm{mV}$ at $10 \mathrm{~mA} \mathrm{~cm}{ }^{-2}$ and a large cathodic current density of $65.6 \mathrm{~mA} \mathrm{~cm}^{-2}$ at $200 \mathrm{mV}$ (Fig. 5). ${ }^{122}$ Nitrogen doping promoted the conductivity of composites, and the embedded mode of $\mathrm{MoS}_{2}$ NSs and CNFs greatly improved their stability and catalytic activity. $\mathrm{CoS}_{2} \mathrm{NW} / \mathrm{MoS}_{2}$ NSs supported on carbon cloth also exhibits excellent HER performance and prominent electrochemical durability. ${ }^{\mathbf{1 1 2}}$ However, most of the conductive substrates are inert for the HER and will decrease the density of active sites of TMDs NSs, therefore, balancing the active sites and conductivity of electrochemical catalysts remains a knotty problem. ${ }^{\mathbf{1 2 4}}$ On the other hand, 

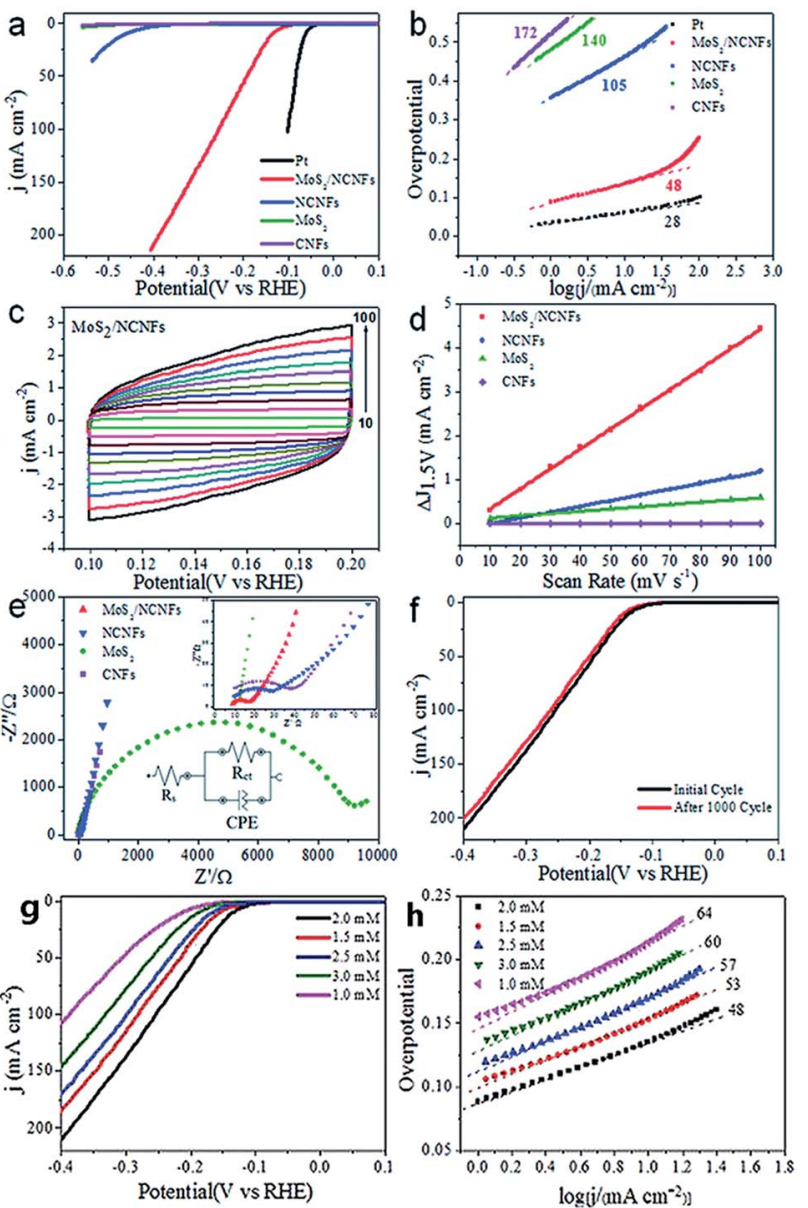

Fig. 5 Electrocatalytic performance of $\mathrm{MoS}_{2} / \mathrm{NCNFs}$. (a) Polarization curves, (b) Tafel plots, (c) electrochemical cyclic voltammogram of $\mathrm{MoS}_{2} / \mathrm{NCNFs}$ at different potential scanning rates, (d) the $C_{\mathrm{dl}}$ of different materials obtained at $0.15 \mathrm{~V}$ vs. RHE, (e) Nyquist plots and ( $f$ ) stability of the $\mathrm{MoS}_{2} / \mathrm{NCNFs}$ with the initial polarization curve (black curve) and after 1000 cycles (red curve). (g) Polarization curves (g) and (h) the corresponding Tafel plots of $\mathrm{MoS}_{2}$ /NCNFs prepared at different concentration of Mo precursor. Adapted from ref. 122 with permission of The Royal Society of Chemistry.

integrated with noble metal nanostructures, TMDs can achieve a high electrocatalytic performance toward HER. ${ }^{\mathbf{1 3 8}}$ For instance, Au NPs coated on TMDs NSs can largely improve the charge transport along interplanar directions and inhibited restacking, which improved the accessibility of protons to the catalytically active sites. ${ }^{\mathbf{1 1 8}} \mathrm{Hou}$ et al. reported the growth of Pt $\mathrm{NPs} / \mathrm{MoS}_{2}$ NSs on the surface of carbon fiber and demonstrated an overpotential of $-5 \mathrm{mV}$ and a corresponding Tafel slope of $53.6 \mathrm{mV} \mathrm{dec}{ }^{-1} \cdot{ }^{139}$ The large specific surface area of TMDs not only effectively collect and transport charges, but also provides plenty of nucleation sites for the growth of metal NPs. ${ }^{138}$

In 1972, Fujishima et al. demonstrated a green approach to split water utilizing $\mathrm{TiO}_{2}$ as a photochemical catalyst, which offers a promising way for clean and low-cost production of hydrogen via solar energy. ${ }^{\mathbf{1 4 0 , 1 4 1}}$ However, the rapid recombination of the electron-hole pairs and low activation ability of the surface reduced the amount of charge, resulting in a low photocatalytic efficiency. ${ }^{85}$ Introducing TMDs as co-catalysts which serve as the reaction sites can promote the charge separation and transport. ${ }^{105}$ Indeed, $\mathrm{MoS}_{2}$ NSs coated on a $\mathrm{TiO}_{2}$ surface significantly facilitated the separation of the photo-induced carriers, which resulted in a higher photocurrent and improved broad spectrum photocatalytic properties. ${ }^{142,143}$ Moreover, Zhou et al. demonstrated that nitrogen self-doped $\mathrm{MoS}_{2}$ NSs integrated with $\mathrm{MnO}_{2}$ NBs exhibited excellent performance with an onset potential of $-156 \mathrm{mV}$ ( $v s$. RHE), a large current density, a small Tafel slope of $47.5 \mathrm{mV} \mathrm{dec}^{-1}$ and outstanding electrochemical durability. ${ }^{\mathbf{1 4 4}}$ Nitrogen doping provides a localized state near the Fermi energy in $\mathrm{MoS}_{2}$ band gap and thus leads to a high electronic conductivity of the heterostructure. Besides, electron-rich sites are beneficial to attract $\mathrm{H}^{+}$to the catalyst surface and gains an enhanced HER activity. Plasmon-excited hot electrons injection mechanism is also an efficient and promising route for the improvement of catalyst activity. ${ }^{\mathbf{1 1 1}}$ However, achieving a faster electrons injection from plasmonic metal to semiconductor than the recombination process is still a significant challenge.

\subsection{Lithium battery}

Rechargeable Li batteries with high energy density, good cycle life, and blameless power performance has become one of the most important energy storage devices in recent years. ${ }^{145}$ To date, silicon, metal alloys, metal oxides and TMDs have been widely explored as the replacement of graphite anodes in Li-ion batteries (LIB). ${ }^{\mathbf{1 4 6 - 1 4 8}}$ The high surface-to-volume ratio and short diffusion path of TMD NSs render it as a brilliant electrode material for LIBs. For instance, Hwang et al. reported graphenelike $\mathrm{MoS}_{2}$ nanoplates showing a reversible capacity of $912 \mathrm{~mA} \mathrm{~h}$ $\mathrm{g}^{-1}$ at a rate of $1 \mathrm{C}$ and excellent cycling stability when fabricated in LIBs. ${ }^{149}$ To further improve the cycling stability and rate capability performance of TMDs, integrating LDNs such as Au NPs and $\mathrm{TiO}_{2}$ NPs is an effective approach. ${ }^{\mathbf{1 2 0 , 1 5 0}}$ Guo et al. demonstrated that GQDs/ $\mathrm{MoS}_{2}$ exhibits excellent electrochemical lithium storage properties with a high reversible capacity (1099 $\mathrm{mA} \mathrm{h} \mathrm{g}^{-1}$ at $100 \mathrm{~mA} \mathrm{~g}^{-1}$ ), good cyclic stability, as well as excellent rate performance $\left(660 \mathrm{~mA} \mathrm{~h} \mathrm{~g}{ }^{-1}\right.$ at $5000 \mathrm{~mA}$ $\mathrm{g}^{-1}$ ) as shown in Fig. 6. ${ }^{107}$ GQDs acted as binder enhanced cyclic stability and facilitate the charge transfer within the electrode. Furthermore, it can enlarge the interlayer distance between $\mathrm{MoS}_{2}$ layers which is beneficial for $\mathrm{Li}^{+}$intercalation. Zhou et al. demonstrated that CNFs@MoS ${ }_{2}$ coaxial NFs showed an excellent Li storage properties, such as high specific capacity, good cycling stability, and superior high-rate capability. ${ }^{151}$ The synergistic effect of the two active components leads to a larger capacity and better cyclability.

$\mathrm{TiO}_{2}$ with superior safety and rate capability exhibits excellent performance when employed as anodes materials. ${ }^{152} \mathrm{Li}$ et al. demonstrated that $\mathrm{TiO}_{2} @ \mathrm{MoS}_{2}$ heterostructure displayed a high initial discharge capacity of $862 \mathrm{~mA} \mathrm{~h} \mathrm{~g}{ }^{-1}$, and it maintained at $544 \mathrm{~mA} \mathrm{~h} \mathrm{~g}^{-1}$ even after 100 cycles. ${ }^{125}$ The synergistic effects of $\mathrm{TiO}_{2} \mathrm{NW}$ and ultrathin $\mathrm{MoS}_{2}$ shorten the $\mathrm{Li}^{+}$diffusion paths for rapid charge transfer, and improved cycling stability of the system at high rates. Xue et al. demonstrated a $\mathrm{Fe}_{3} \mathrm{O}_{4} \mathrm{NPs} /$ $\mathrm{MoS}_{2}$ nanostructures as an anode for LIBs with a superior cyclic 

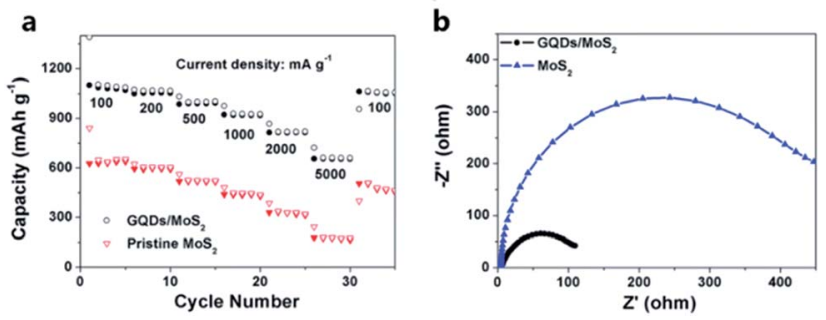

Fig. 6 (a) Rate capabilities and (b) electrochemical impedance spectroscopy spectra of GQDs/MoS 2 and pristine $\mathrm{MoS}_{2}$ electrodes. Adapted from ref. 107 with permission of The Royal Society of Chemistry.

and rate performances. ${ }^{153} \mathrm{Fe}_{3} \mathrm{O}_{4}$ NPs serving as spacers and effectively stabilize the integrated structure, facilitating the $\mathrm{MoS}_{2}$ surfaces accessible to electrolyte during charge/discharge processes, thereby hindering the fast fading of reversible capacities. The heterostructure contribute a 1033 and $224 \mathrm{~mA} \mathrm{~h}$ $\mathrm{g}^{-1}$ at current densities of 2000 and $10000 \mathrm{~mA} \mathrm{~g}^{-1}$, respectively. The $\mathrm{MoS}_{2}$ NSs provided a high reversible capacity and $\mathrm{Fe}_{3} \mathrm{O}_{4}$ NPs offered a high rate performance. In addition, $\mathrm{MoS}_{2}$ has been reported as cathode material for lithium-oxygen $\left(\mathrm{Li}-\mathrm{O}_{2}\right)$ batteries, which exhibits a $85 \%$ round-trip efficiency and good reversibility. ${ }^{159}$ Table 2 lists some typical examples comprised of different components for lithium storage performances.

TMDs anodes have been studied for many years, yet there are still many challenges. The large irreversible capacity was observed in the first cycle, indicating that a large portion of $\mathrm{Li}^{+}$ ions could not be utilized again in the following cycles, and the relatively high voltage behavior of the TMDs limited its applications. ${ }^{160}$ Nevertheless, TMDs is a promising anodes material owing to superior capacity and rate capability. ${ }^{8}$

\subsection{Sensor and detector}

TMDs materials with a tuneable band gap applied in sensors and detectors usually exhibited high selectivity and rapid detection. ${ }^{161-164}$ Using first-principles calculations, Yue et al. found that small gas molecules can be physically absorbed on monolayer $\mathrm{MoS}_{2}$, and determined the most stable adsorption configuration and adsorption energy ${ }^{165}$ The band structure of monolayer $\mathrm{MoS}_{2}$ will not significantly be altered though small gas molecules are absorbed. Many reports have demonstrated
TMDs-based sensors, when integrated with noble metal or metal oxide semiconductors, exhibiting an enhanced performance compared with individual component. ${ }^{166-168}$ For instance, He et al. demonstrated that Pt NPs deposited on $\mathrm{MoS}_{2}$ NSs exhibits high sensitivity for $\mathrm{NO}_{2}$ detection. ${ }^{169}$ Upon the adsorption of gas, the Schottky barrier between Pt NPs and $\mathrm{MoS}_{2}$ channel is changed, which may help explain the increased sensitivity of $\mathrm{MoS}_{2}$ thin film. ${ }^{170,171}$ In addition, Kuru et al. demonstrated Pd $\mathrm{NPs} / \mathrm{MoS}_{2}$ NS could show a highly sensitivity for $\mathrm{H}_{2}$ detection at room temperature and the sensor exhibits a response of around 10 toward $50000 \mathrm{ppm} \mathrm{H}_{2}$ with a response and recovery time of 40 and $83 \mathrm{~s}$, respectively. ${ }^{109}$ TMDs-based biosensor can effectively and sensitively detect biomolecule. ${ }^{172,173}$ Using molecular dynamics and density functional theory simulation, Aluru et al. demonstrated that monolayer $\mathrm{MoS}_{2}$ is an promising material for DNA sequencing technology. ${ }^{174}$ Thiol modified monolayer $\mathrm{MoS}_{2}$ integrated with Au NPs can largely enhance the DNA adsorption about 1 order of magnitude. ${ }^{175} \mathrm{MoS}_{2}$ NSs exhibited different PL properties toward single-strained DNA versus double strained DNA when the concentration of DNA solution increased, which can be used for rapid and selective detection of DNA nucleoside chains. In another case, Su et al. reported a $\mathrm{Au} \mathrm{NPs} / \mathrm{MoS}_{2}$ biosensor that could detect glucose in a concentration range from 10 to $300 \mu \mathrm{M}$ with a detection limit of $2.8 \mu \mathrm{M} .{ }^{176}$ Furthermore, the sensor also displays good reproducibility and longterm stability, indicating its potential to be applied for determination of glucose concentration in human serum. In addition, Shao et al. reported an electrochemical dopamine (DA) sensor based on Au NPs@MoS ${ }_{2}$ nanocomposite, and the detection concentration of DA ranges from 0.1 to $200 \mathrm{mM}$, with a detection limit of $80 \mathrm{nM}(\mathrm{S} / \mathrm{N}=3),{ }^{121}$ and the sensor can also detect DA in ascorbic acid existed environment.

Monolayer $\mathrm{MoS}_{2}$ with a direct bandgap of $1.9 \mathrm{eV}$ is extremely attractive for photodetector. Kis et al. reported a monolayer $\mathrm{MoS}_{2}$ photodetector with a photoresponsivity of $880 \mathrm{~A} \mathrm{~W}^{-1}$ at a wavelength of $561 \mathrm{~nm}$ and a photoresponse in the $400-680 \mathrm{~nm}$ range. ${ }^{177}$ However, the slow responsivity is an important limiting factor for application. To address this situation, Kufer et al. demonstrated PbS QDs decorated $\mathrm{MoS}_{2}$ for photodetector could achieve a high responsivity of $6 \times 10^{5} \mathrm{~A} \mathrm{~W}^{-1}$, and the responsivity is higher than individual PbS QDs and $\mathrm{MoS}_{2}$-based detectors. ${ }^{178}$ Owing to the effect of reverse electric induced by increasing separated charge carriers, the responsivity presents a decrease trend with increasing optical intensity. In addition,

Table 2 The lithium storage performances of TMDs based anode materials

\begin{tabular}{|c|c|c|c|c|}
\hline Anode materials & Current rate & Initial capacity $\left(\mathrm{mA} \mathrm{h} \mathrm{g}^{-1}\right)$ & Capacity retention $\left(\mathrm{mA} \mathrm{h} \mathrm{g}^{-1}\right) /($ cycles $)$ & Ref. \\
\hline $\mathrm{MoS}_{2}$ & $1 \mathrm{C}$ & 1062 & $907 / 50$ & 149 \\
\hline Graphene- $-\mathrm{MoS}_{2}$ & $100 \mathrm{~mA} \mathrm{~g}^{-1}$ & 1571 & $1187 / 100$ & 154 \\
\hline GQDs-MoS 2 & $100 \mathrm{~mA} \mathrm{~g}^{-1}$ & 1394 & $1031 / 80$ & 107 \\
\hline $\mathrm{TiO}_{2}-\mathrm{MoS}_{2}$ & $0.1 \mathrm{C}$ & 588 & $350 / 100$ & 155 \\
\hline Carbon- $-\mathrm{TiO}_{2}-\mathrm{MoS}_{2}$ & $100 \mathrm{~mA} \mathrm{~g}^{-1}$ & 941.6 & $805 / 100$ & 156 \\
\hline
\end{tabular}


metal plasmon LDNs with near-field oscillation and scattering effect can effectively improve the photocurrent response and light absorption of TMDs, which can be applied to exploit plasmon resonance-based devices. ${ }^{179}$ Although great progress has been made in this area, the mechanism and principles of electron transfer of TMDs is remain unclear. ${ }^{\mathbf{1 8 0}}$

\section{Conclusion}

In summary, the integration of LDNs and TMD exhibits a tailored performance due to synergistic effects. LDN materials with dissimilar properties that differ from their bulk counterparts effectively mitigate the genetic disadvantages of TMDs, while TMD NSs with controllable size and thickness provided suitable surface areas for LDNs to integrate. For LDN/TMD heterostructures, many synthesis methods such as self-assembly and hydrothermal methods have been developed for preparation via one step or multi-step approaches. The shape and distribution of LDNs can be controlled by changing the component ratio of precursor solution or modifying the surface of TMDs and have a large impact on the system performance. Through incorporating different types of LDNs, TMD heterostructures with unique properties have been applied in various areas. As a promising candidate to replace Pt catalyst for hydrogen production, TMDs integrated with LDNs solve the limitation of low conductivity, and shows a high chemical stability and excellent electrocatalytic activities. As electrode materials for LIBs, the heterostructure contributes a high reversible capacity and an excellent rate capability. Owing to the high surface-to-volume ratio and tuneable band gap of TMDs, the sensors combine with LDNs exhibit a high selectivity to detect biomolecules and gas molecules, and have great impacts in the field of photodetection.

Although extensive investigations have focused on LDNs/ TMDs heterostructures, several limitations still exist. Firstly, LDNs reported in most papers are noble metals, metal oxides, metal dichalcogenides and graphite derivatives, the fields may expand to organic materials in future. Secondly, a method to prepare TMD NSs with excellent morphology and desired properties is still necessary. Heteroatom doping can offer TMDs with various new or improved optical and structural properties, ${ }^{\mathbf{1 8 1}}$ which may provide some inspiration for further development of LDNs/TMDs heterostructures. Finally, how the spatial organization and distribution affecting the system performances have not been fully investigated yet. ${ }^{\mathbf{1 8 2}}$ Many reports are restricted to concern the component of the heterostructure, therefore more studies are still required to optimize the fabricated structures. Nonetheless, the study of TMDs is just in the infant stage and a greater potential is waiting for exploration.

\section{Acknowledgements}

The authors gratefully acknowledge funding from National Natural Science Foundation of China 51272038, National Natural Science Foundation of China 51302030, National Natural Science Foundation of China 61474015 and National Program on Key Basic Research Project (973 Program) 2013 CB933301.

\section{References}

1 F. Bonaccorso, L. Colombo, G. Yu, M. Stoller, V. Tozzini, A. C. Ferrari, R. S. Ruoff and V. Pellegrini, Science, 2015, 347, 1246501.

2 X. Wang, G. Sun, P. Routh, D. H. Kim, W. Huang and P. Chen, Chem. Soc. Rev., 2014, 43, 7067-7098.

3 F. Xia, H. Wang, D. Xiao, M. Dubey and A. Ramasubramaniam, Nat. Photonics, 2014, 8, 899-907.

4 D. Jariwala, V. K. Sangwan, L. J. Lauhon, T. J. Marks and M. C. Hersam, ACS Nano, 2014, 8, 1102-1120.

5 M. Xu, T. Liang, M. Shi and H. Chen, Chem. Rev., 2013, 113, 3766-3798.

6 S. Z. Butler, S. M. Hollen, L. Cao, Y. Cui, J. A. Gupta, H. R. Gutiérrez, T. F. Heinz, S. S. Hong, J. Huang, A. F. Ismach, E. Johnston-Halperin, M. Kuno, V. V. Plashnitsa, R. D. Robinson, R. S. Ruoff, S. Salahuddin, J. Shan, L. Shi, M. G. Spencer, M. Terrones, W. Windl and J. E. Goldberger, ACS Nano, 2013, 7, 2898-2926.

7 L. Tao, D. Wang, S. Jiang, Y. Liu, Q. Xie, H. Tian, N. Deng, X. Wang, Y. Yang and T.-L. Ren, J. Semicond., 2016, 37, 041001.

8 H. Li, Y. Shi, M.-H. Chiu and L.-J. Li, Nano Energy, 2015, 18, 293-305.

9 V. Sorkin, H. Pan, H. Shi, S. Y. Quek and Y. W. Zhang, Crit. Rev. Solid State Mater. Sci., 2014, 39, 319-367.

10 M. Chhowalla, H. S. Shin, G. Eda, L. J. Li, K. P. Loh and H. Zhang, Nat. Chem., 2013, 5, 263-275.

11 L. Yuwen, F. Xu, B. Xue, Z. Luo, Q. Zhang, B. Bao, S. Su, L. Weng, W. Huang and L. Wang, Nanoscale, 2014, 6, 5762-5769.

12 J. A. Wilson and A. D. Yoffe, Adv. Phys., 1969, 18, 193-335.

13 K. F. Mak, C. Lee, J. Hone, J. Shan and T. F. Heinz, Phys. Rev. Lett., 2010, 105, 136805.

14 Q. H. Wang, K. Kalantar-Zadeh, A. Kis, J. N. Coleman and M. S. Strano, Nat. Nanotechnol., 2012, 7, 699-712.

15 X. Tong, E. Ashalley, F. Lin, H. Li and Z. M. Wang, NanoMicro Lett., 2015, 7, 203-218.

16 A. K. Geim and I. V. Grigorieva, Nature, 2013, 499, 419-425. 17 H. Wang, F. Liu, W. Fu, Z. Fang, W. Zhou and Z. Liu, Nanoscale, 2014, 6, 12250-12272.

18 J. Kang, J. Li, S. S. Li, J. B. Xia and L. W. Wang, Nano Lett., 2013, 13, 5485-5490.

19 N. Myoung, K. Seo, S. J. Lee and G. Ihm, ACS Nano, 2013, 7, 7021-7027.

20 H. Zheng, Y. Li, H. Liu, X. Yin and Y. Li, Chem. Soc. Rev., 2011, 40, 4506-4524.

21 B. Luo, G. Liu and L. Wang, Nanoscale, 2016, 8, 6904-6920.

22 W. T. Sun, Y. Yu, H. Y. Pan, X. F. Gao, Q. Chen and L. M. Peng, J. Am. Chem. Soc., 2008, 130, 1124-1125.

23 A. Cao, Z. Liu, S. Chu, M. Wu, Z. Ye, Z. Cai, Y. Chang, S. Wang, Q. Gong and Y. Liu, Adv. Mater., 2010, 22, 103-106.

24 H. Kim and K. Yong, Phys. Chem. Chem. Phys., 2013, 15, 2109-2116.

25 H. Zhao, G. Sirigu, A. Parisini, A. Camellini, G. Nicotra, F. Rosei, V. Morandi, M. Zavelani-Rossi and A. Vomiero, Nanoscale, 2016, 8, 4217-4226. 
26 E. A. Anyebe, M. K. Rajpalke, T. D. Veal, C. J. Jin, Z. M. Wang and Q. D. Zhuang, Nano Res., 2014, 8, 1309-1319.

27 G. Vasseur, Y. Fagot-Revurat, M. Sicot, B. Kierren, L. Moreau, D. Malterre, L. Cardenas, G. Galeotti, J. Lipton-Duffin, F. Rosei, M. Di Giovannantonio, G. Contini, P. Le Fevre, F. Bertran, L. Liang, V. Meunier and D. F. Perepichka, Nat. Commun., 2016, 7, 10235.

28 R. Brayner and F. Bozon-Verduraz, Phys. Chem. Chem. Phys., 2003, 5, 1457-1466.

29 Y. Xia, P. Yang, Y. Sun, Y. Wu, B. T. Mayers, B. D. Gates, Y. Yin, F. Kim and H. Yan, Adv. Mater., 2003, 15, 353-389.

30 C. Frigerio, D. S. Ribeiro, S. S. Rodrigues, V. L. Abreu, J. A. Barbosa, J. A. Prior, K. L. Marques and J. L. Santos, Anal. Chim. Acta, 2012, 735, 9-22.

31 R.-H. Tao, J.-M. Wu, H.-X. Xue, X.-M. Song, X. Pan, X.-Q. Fang, X.-D. Fang and S.-Y. Dai, J. Power Sources, 2010, 195, 2989-2995.

32 W. Wen, J. M. Wu, Y. Z. Jiang, S. L. Yu, J. Q. Bai, M. H. Cao and J. Cui, Sci. Rep., 2015, 5, 11804.

33 Z. Yin, B. Chen, M. Bosman, X. Cao, J. Chen, B. Zheng and H. Zhang, Small, 2014, 10, 3537-3543.

34 B. Li, J. M. Wu, T. T. Guo, M. Z. Tang and W. Wen, Nanoscale, 2014, 6, 3046-3050.

35 D. Deng, K. S. Novoselov, Q. Fu, N. Zheng, Z. Tian and X. Bao, Nat. Nanotechnol., 2016, 11, 218-230.

36 X. Chia, A. Y. Eng, A. Ambrosi, S. M. Tan and M. Pumera, Chem. Rev., 2015, 115, 11941-11966.

37 F. Reale, K. Sharda and C. Mattevi, Applied Materials Today, 2016, 3, 11-22.

38 Z. He and W. Que, Applied Materials Today, 2016, 3, 23-56.

39 W. Guo, J. Yin, H. Qiu, Y. Guo, H. Wu and M. Xue, Friction, 2014, 2, 209-225.

40 J. Loomis and B. Panchapakesan, Nanotechnology, 2012, 23, 215501.

41 K. Peng, Y. Xu, Y. Wu, Y. Yan, S. T. Lee and J. Zhu, Small, 2005, 1, 1062-1067.

42 P. Yu, J. Wu, S. Liu, J. Xiong, C. Jagadish and Z. M. Wang, Nano Today, 2016, 11, 704-737.

43 L. Hu and G. Chen, Nano Lett., 2007, 7, 3249-3252.

44 X. Huang, I. H. El-Sayed, W. Qian and M. A. El-Sayed, J. Am. Chem. Soc., 2006, 128, 2115-2120.

45 S. A. Maier and H. A. Atwater, J. Appl. Phys., 2005, 98, 011101.

46 M. R. Jones, K. D. Osberg, R. J. Macfarlane, M. R. Langille and C. A. Mirkin, Chem. Rev., 2011, 111, 3736-3827.

47 J. Wu, P. Yu, A. S. Susha, K. A. Sablon, H. Chen, Z. Zhou, H. Li, H. Ji, X. Niu, A. O. Govorov, A. L. Rogach and Z. M. Wang, Nano Energy, 2015, 13, 827-835.

48 S. Eustis and M. A. El-Sayed, Chem. Soc. Rev., 2006, 35, 209-217. 49 B. O. Dabbousi, J. Rodriguez-Viejo, F. V. Mikulec, J. R. Heine, H. Mattoussi, R. Ober, K. F. Jensen and M. G. Bawendi, J. Phys. Chem. B, 1997, 101, 9463-9475.

50 V.-V. Truong, P. Courteau and J. Singh, J. Appl. Phys., 1987, 62, 4863.

51 X. Xue, W. Ji, Z. Mao, H. Mao, Y. Wang, X. Wang, W. Ruan, B. Zhao and J. R. Lombardi, J. Phys. Chem. C, 2012, 116, 8792-8797.
52 Y. Cui, P. P. Shum, G. Y. Wang, H. Chang, X. Q. Dinh, M. Jiang and G. Humbert, Sensors, 2011, 371-374.

53 A. Convertino, M. Cuscunà, F. Martelli, M. G. Manera and

R. Rella, J. Phys. Chem. C, 2014, 118, 685-690.

54 P. Claus, A. Bruckner, C. Mohr and H. Hofmeister, J. Am. Chem. Soc., 2000, 122, 11430-11439.

55 D. M. Sagar, R. R. Cooney, S. L. Sewall, E. A. Dias, M. M. Barsan, I. S. Butler and P. Kambhampati, Phys. Rev. B: Condens. Matter Mater. Phys., 2008, 77.

56 D. Gao, H. Zhou, J. Wang, S. Miao, F. Yang, G. Wang, J. Wang and X. Bao, J. Am. Chem. Soc., 2015, 137, 4288-4291.

57 K. Das, K. Rawat, R. Patel and H. B. Bohidar, RSC Adv., 2016, 6, 46744-46754.

58 P. Yu, J. Wu, E. Ashalley, A. Govorov and Z. Wang, J. Phys. D: Appl. Phys., 2016, 49, 365101.

59 B. Hamawandi, M. Noroozi, G. Jayakumar, A. Ergül, K. Zahmatkesh, M. S. Toprak and H. H. Radamson, J. Semicond., 2016, 37, 102001.

60 S. A. Han, R. Bhatia and S.-W. Kim, Nano Convergence, 2015, 2.

61 C. Xia and J. Li, J. Semicond., 2016, 37, 051001.

62 W. Zhao, R. M. Ribeiro and G. Eda, Acc. Chem. Res., 2015, 48, 91-99.

63 Y. Kang, S. Najmaei, Z. Liu, Y. Bao, Y. Wang, X. Zhu, N. J. Halas, P. Nordlander, P. M. Ajayan, J. Lou and Z. Fang, Adv. Mater., 2014, 26, 6467-6471.

64 M. Acerce, D. Voiry and M. Chhowalla, Nat. Nanotechnol., 2015, 10, 313-318.

65 K. F. Mak, K. He, J. Shan and T. F. Heinz, Nat. Nanotechnol., 2012, 7, 494-498.

66 Z. Yin, H. Li, H. Li, L. Jiang, Y. Shi, Y. Sun, G. Lu, Q. Zhang, X. Chen and H. Zhang, ACS Nano, 2013, 6, 74-80.

67 S. Bhattacharyya and A. K. Singh, Phys. Rev. B: Condens. Matter Mater. Phys., 2012, 86.

68 A. Kuc, N. Zibouche and T. Heine, Phys. Rev. B: Condens. Matter Mater. Phys., 2011, 83, 245213.

69 A. Splendiani, L. Sun, Y. Zhang, T. Li, J. Kim, C. Y. Chim, G. Galli and F. Wang, Nano Lett., 2010, 10, 1271-1275.

70 K. F. Mak, C. Lee, J. Hone, J. Shan and T. F. Heinz, Phys. Rev. Lett., 2010, 105, 136805.

71 M. Amani, D. Lien, D. Kiriya, J. Xiao, A. Azcatl, J. Noh, S. R. Madhvapathy, R. Addou, K. C. Santosh and M. Dubey, Science, 2015, 350, 1065-1068.

72 P. Tonndorf, R. Schmidt, P. Bottger, X. Zhang, J. Borner, A. Liebig, M. Albrecht, C. Kloc, O. Gordan, D. R. Zahn, S. Michaelis de Vasconcellos and R. Bratschitsch, Opt. Express, 2013, 21, 4908-4916.

73 C. Li, Y. Yu, M. Chi and L. Cao, Nano Lett., 2013, 13, 948-953. 74 B. Mukherjee and E. Simsek, Plasmonics, 2015, 11, 285-289. 75 X. Yang, W. Liu, M. Xiong, Y. Zhang, T. Liang, J. Yang, M. Xu, J. Ye and H. Chen, J. Mater. Chem. A, 2014, 2, 14798. 76 B. Zhu, B. Lin, Y. Zhou, P. Sun, Q. Yao, Y. Chen and B. Gao, J. Mater. Chem. A, 2014, 2, 3819.

77 Y. Yan, X. Ge, Z. Liu, J. Y. Wang, J. M. Lee and X. Wang, Nanoscale, 2013, 5, 7768-7771.

78 W. Zhou, Z. Yin, Y. Du, X. Huang, Z. Zeng, Z. Fan, H. Liu, J. Wang and H. Zhang, Small, 2013, 9, 140-147. 
79 K. Zhang, Y. Zhang, T. Zhang, W. Dong, T. Wei, Y. Sun, X. Chen, G. Shen and N. Dai, Nano Res., 2014, 8, 743-750.

80 X. Dai, K. Du, Z. Li, H. Sun, Y. Yang, W. Zhang and X. Zhang, Int. J. Hydrogen Energy, 2015, 40, 8877-8888.

81 M. Shen, Z. Yan, L. Yang, P. Du, J. Zhang and B. Xiang, Chem. Commun., 2014, 50, 15447-15449.

82 U. Bhanu, M. R. Islam, L. Tetard and S. I. Khondaker, Sci. Rep., 2014, 4, 5575.

83 K. K. Amara, Y. Chen, Y.-C. Lin, R. Kumar, E. Okunishi, K. Suenaga, S. Y. Quek and G. Eda, Chem. Mater., 2016, 28, 2308-2314.

84 B. Ouyang, Z. Mi and J. Song, J. Phys. Chem. C, 2016, 120, 8927-8935.

85 S. Bai, L. Wang, X. Chen, J. Du and Y. Xiong, Nano Res., 2014, 8, 175-183.

86 W. Cao, V. Pankratov, M. Huttula, X. Shi, S. Saukko, Z. Huang and M. Zhang, Mater. Chem. Phys., 2015, 158, 89-95.

87 Y. Shi, J. K. Huang, L. Jin, Y. T. Hsu, S. F. Yu, L. J. Li and H. Y. Yang, Sci. Rep., 2013, 3, 1839.

88 S. Su, M. Zou, H. Zhao, C. Yuan, Y. Xu, C. Zhang, L. Wang, C. Fan and L. Wang, Nanoscale, 2015, 7, 19129-19135.

89 H. Wu, Y. Wu, X. Chen, Y. Ma, M. Xu, W. Wei, J. Pan and X. Xiong, $R S C A d v .$, 2016, 6, 23161-23168.

90 X. Wang, H. Feng, Y. Wu and L. Jiao, J. Am. Chem. Soc., 2013, 135, 5304-5307.

91 H. Li, X. Qi, J. Wu, Z. Zeng, J. Wei and H. Zhang, ACS Nano, 2013, 7, 2842-2849.

92 S. M. Tan, Z. Sofer, J. Luxa and M. Pumera, ACS Catal., 2016, 6, 4594-4607.

93 A. Ambrosi, Z. Sofer and M. Pumera, Small, 2015, 11, 605612.

94 A. Ambrosi, Z. Sofer and M. Pumera, Chem. Commun., 2015, 51, 8450-8453.

95 J. Zheng, H. Zhang, S. Dong, Y. Liu, C. T. Nai, H. S. Shin, H. Y. Jeong, B. Liu and K. P. Loh, Nat. Commun., 2014, 5, 2995.

96 E. Varrla, C. Backes, K. R. Paton, A. Harvey, Z. Gholamvand, J. McCauley and J. N. Coleman, Chem. Mater., 2015, 27, 1129-1139.

97 Y. H. Lee, X. Q. Zhang, W. Zhang, M. T. Chang, C. T. Lin, K. D. Chang, Y. C. Yu, J. T. Wang, C. S. Chang, L. J. Li and T. W. Lin, Adv. Mater., 2012, 24, 2320-2325.

$98 \mathrm{X}$. Li and H. Zhu, Journal of Materiomics, 2015, 1, 33-44.

99 R. Lv, J. A. Robinson, R. E. Schaak, D. Sun, Y. Sun, T. E. Mallouk and M. Terrones, Acc. Chem. Res., 2015, 48, 56-64.

100 J. T. Jang, S. Jeong, J. W. Seo, M. C. Kim, E. Sim, Y. Oh, S. Nam, B. Park and J. Cheon, J. Am. Chem. Soc., 2011, 133, 7636-7639.

101 S. Jeong, D. Yoo, J. T. Jang, M. Kim and J. Cheon, J. Am. Chem. Soc., 2012, 134, 18233-18236.

102 Y. Dai, X. H. Yan, X. Wu, D. W. Sha, M. Chen, H. Zou, J. Ren and X. N. Cheng, Mater. Lett., 2016, 173, 203-206.

103 J. Lu, J. H. Lu, H. Liu, B. Liu, L. Gong, E. S. Tok, K. P. Loh and C. H. Sow, Small, 2015, 11, 1792-1800.

104 D. B. Nimbalkar, H.-H. Lo, P. V. R. K. Ramacharyulu and S.-C. Ke, $R S C A d v .$, 2016, 6, 31661-31667.
105 Y. J. Yuan, F. Wang, B. Hu, H. W. Lu, Z. T. Yu and Z. G. Zou, Dalton Trans., 2015, 44, 10997-11003.

106 H. Yan, P. Song, S. Zhang, Z. Yang and Q. Wang, RSC Adv., 2015, 5, 79593-79599.

107 J. Guo, H. Zhu, Y. Sun, L. Tang and X. Zhang, J. Mater. Chem. A, 2016, 4, 4783-4789.

108 H. Sun, J. Chao, X. Zuo, S. Su, X. Liu, L. Yuwen, C. Fan and L. Wang, RSC Adv., 2014, 4, 27625.

109 C. Kuru, C. Choi, A. Kargar, D. Choi, Y. J. Kim, C. H. Liu, S. Yavuz and S. Jin, Adv. Sci., 2015, 2, 1500004.

110 M. Zirak, M. Zhao, O. Moradlou, M. Samadi, N. Sarikhani, Q. Wang, H. L. Zhang and A. Z. Moshfegh, Sol. Energy Mater. Sol. Cells, 2015, 141, 260-269.

111 Y. Shi, J. Wang, C. Wang, T. T. Zhai, W. J. Bao, J. J. Xu, X. H. Xia and H. Y. Chen, J. Am. Chem. Soc., 2015, 137, 7365-7370.

112 J. Huang, D. Hou, Y. Zhou, W. Zhou, G. Li, Z. Tang, L. Li and S. Chen, J. Mater. Chem. A, 2015, 3, 22886-22891.

113 Y. Huang, Y. E. Miao, L. Zhang, W. W. Tjiu, J. Pan and T. Liu, Nanoscale, 2014, 6, 10673-10679.

114 S. Xu, D. Li and P. Wu, Adv. Funct. Mater., 2015, 25, 11271136.

115 G. M. Whitesides and B. Grzybowski, Science, 2002, 295, 2418. 116 M. Grzelczak, J. Vermant, E. M. Furst and L. M. Liz-Marzan, ACS Nano, 2010, 4, 3591-3605.

117 Y.-F. Zhao, Z.-Y. Yang, Y.-X. Zhang, L. Jing, X. Guo, Z. Ke, P. Hu, G. Wang, Y.-M. Yan and K.-N. Sun, J. Phys. Chem. C, 2014, 118, 14238-14245.

118 J. Kim, S. Byun, A. J. Smith, J. Yu and J. Huang, J. Phys. Chem. Lett., 2013, 4, 1227-1232.

119 M. Yoshimura and K. Byrappa, J. Mater. Sci., 2007, 43, 20852103.

120 P. Zhang, X. Lu, Y. Huang, J. Deng, L. Zhang, F. Ding, Z. Su, G. Wei and O. G. Schmidt, J. Mater. Chem. A, 2015, 3, 1456214566.

121 S. Su, H. Sun, F. Xu, L. Yuwen and L. Wang, Electroanalysis, 2013, 25, 2523-2529.

122 Y. Guo, X. Zhang, X. Zhang and T. You, J. Mater. Chem. A, 2015, 3, 15927-15934.

123 V. O. Koroteev, L. G. Bulusheva, I. P. Asanov, E. V. Shlyakhova, D. V. Vyalikh and A. V. Okotrub, J. Phys. Chem. C, 2011, 115, 21199-21204.

124 K. Zhang, Y. Zhao, S. Zhang, H. Yu, Y. Chen, P. Gao and C. Zhu, J. Mater. Chem. A, 2014, 2, 18715-18719.

125 X. Li, W. Li, M. Li, P. Cui, D. Chen, T. Gengenbach, L. Chu, H. Liu and G. Song, J. Mater. Chem. A, 2015, 3, 2762-2769.

126 S. Ding, J. S. Chen and X. W. Lou, Chemistry, 2011, 17, 13142-13145.

127 Y. Huang, Y.-E. Miao, J. Fu, S. Mo, C. Wei and T. Liu, J. Mater. Chem. A, 2015, 3, 16263-16271.

128 J. D. Holladay, J. Hu, D. L. King and Y. Wang, Catal. Today, 2009, 139, 244-260.

129 B. Johnston, M. C. Mayo and A. Khare, Technovation, 2005, 25, 569-585.

130 A. B. Laursen, S. Kegnæs, S. Dahl and I. Chorkendorff, Energy Environ. Sci., 2012, 5, 5577. 
131 Y. Qu, H. Medina, S.-W. Wang, Y.-C. Wang, C.-W. Chen, T.-Y. Su, A. Manikandan, K. Wang, Y.-C. Shih, J.-W. Chang, H.-C. Kuo, C.-Y. Lee, S.-Y. Lu, G. Shen, Z. M. Wang and Y.-L. Chueh, Adv. Mater., 2016, 28, 98319838.

132 E. J. Popczun, J. R. McKone, C. G. Read, A. J. Biacchi, A. M. Wiltrout, N. S. Lewis and R. E. Schaak, J. Am. Chem. Soc., 2013, 135, 9267-9270.

133 W. Sheng, H. A. Gasteiger and Y. Shaohorn, J. Electrochem. Soc., 2010, 157.

134 Y. Zheng, Y. Jiao, M. Jaroniec and S. Z. Qiao, Angew. Chem., 2015, 54, 52-65.

135 T. F. Jaramillo, K. P. Jorgensen, J. Bonde, J. H. Nielsen, S. Horch and I. Chorkendorff, Science, 2007, 317, 100-102.

136 J. Xie, H. Zhang, S. Li, R. Wang, X. Sun, M. Zhou, J. Zhou, X. W. Lou and Y. Xie, Adv. Mater., 2013, 25, 5807-5813.

137 D. McAteer, Z. Gholamvand, N. McEvoy, A. Harvey, E. O'Malley, G. S. Duesberg and J. N. Coleman, ACS Nano, 2016, 10, 672-683.

138 X. Huang, Z. Zeng, S. Bao, M. Wang, X. Qi, Z. Fan and $\mathrm{H}$. Zhang, Molecular therapy : the journal of the American Society of Gene Therapy, 2013, 4, 1444.

139 D. Hou, W. Zhou, X. Liu, K. Zhou, J. Xie, G. Li and S. Chen, Electrochim. Acta, 2015, 166, 26-31.

140 A. Fujishima and K. Honda, Nature, 1972, 238, 37-38.

141 M. Ni, M. K. H. Leung, D. Y. C. Leung and K. Sumathy, Renewable Sustainable Energy Rev., 2007, 11, 401-425.

142 Q. Liu, Z. Pu, A. M. Asiri, A. H. Qusti, A. O. Al-Youbi and X. Sun, J. Nanopart. Res., 2013, 15.

143 H. Li, Y. Wang, G. Chen, Y. Sang, H. Jiang, J. He, X. Li and H. Liu, Nanoscale, 2016, 8, 6101-6109.

144 W. Zhou, D. Hou, Y. Sang, S. Yao, J. Zhou, G. Li, L. Li, H. Liu and S. Chen, J. Mater. Chem. A, 2014, 2, 11358.

145 B. Dunn, H. Kamath and J.-M. Tarascon, Science, 2011, 334, 928.

146 Y. Jing, Z. Zhou, C. R. Cabrera and Z. Chen, J. Mater. Chem. A, 2014, 2, 12104.

147 W. Wen, J.-M. Wu and M.-H. Cao, Nano Energy, 2013, 2, 1383-1390.

148 W. Wen, J. M. Wu and M. H. Cao, Nanoscale, 2014, 6, 12476-12481.

149 H. Hwang, H. Kim and J. Cho, Nano Lett., 2011, 11, 48264830.

150 M. Mao, L. Mei, D. Guo, L. Wu, D. Zhang, Q. Li and T. Wang, Nanoscale, 2014, 6, 12350-12353.

151 F. Zhou, S. Xin, H. W. Liang, L. T. Song and S. H. Yu, Angew. Chem., 2014, 53, 11552-11556.

152 Y. Ren, Z. Liu, F. Pourpoint, A. R. Armstrong, C. P. Grey and P. G. Bruce, Angew. Chem., 2012, 51, 2164-2167.

153 Y. Chen, B. Song, X. Tang, L. Lu and J. Xue, Small, 2014, 10, 1536-1543.

154 K. Chang and W. Chen, ACS Nano, 2011, 5, 4720-4728.

155 J.-Y. Liao, B. D. Luna and A. Manthiram, J. Mater. Chem. A, 2016, 4, 801-806.

156 B. Chen, E. Liu, F. He, C. Shi, C. He, J. Li and N. Zhao, Nano Energy, 2016, 26, 541-549.
157 L. Yang, S. Wang, J. Mao, J. Deng, Q. Gao, Y. Tang and O. G. Schmidt, Adv. Mater., 2013, 25, 1180-1184.

158 D.-A. Zhang, Q. Wang, Q. Wang, J. Sun, L.-L. Xing and X.-Y. Xue, Electrochim. Acta, 2015, 173, 476-482.

159 M. Asadi, B. Kumar, C. Liu, P. Phillips, P. Yasaei, A. Behranginia, P. Zapol, R. F. Klie, L. A. Curtiss and A. Salehi-Khojin, ACS Nano, 2016, 10, 2167-2175.

160 X. Xu, W. Liu, Y. Kim and J. Cho, Nano Today, 2014, 9, 604630.

161 J. Lee, P. Dak, Y. Lee, H. Park, W. Choi, M. A. Alam and S. Kim, Sci. Rep., 2014, 4, 7352.

162 B. Cho, M. G. Hahm, M. Choi, J. Yoon, A. R. Kim, Y. J. Lee, S. G. Park, J. D. Kwon, C. S. Kim, M. Song, Y. Jeong, K. S. Nam, S. Lee, T. J. Yoo, C. G. Kang, B. H. Lee, H. C. Ko, P. M. Ajayan and D. H. Kim, Sci. Rep., 2015, 5, 8052.

163 M. Park, Y. J. Park, X. Chen, Y. K. Park, M. S. Kim and J. H. Ahn, Adv. Mater., 2016, 28, 2556-2562.

164 J. Ye, X. Li, J. Zhao, X. Mei and Q. Li, Nanoscale Res. Lett., 2015, 10, 454.

165 Q. Yue, Z. Shao, S. Chang and J. Li, Nanoscale Res. Lett., 2013, 8, 425.

166 Z. Li, S. Jiang, S. Xu, C. Zhang, H. Qiu, C. Li, Y. Sheng, Y. Huo, C. Yang and B. Man, Sens. Actuators, B, 2016, 230, 645-652.

167 J. Zhao, Z. Zhang, S. Yang, H. Zheng and Y. Li, J. Alloys Compd., 2013, 559, 87-91.

168 H. Yan, P. Song, S. Zhang, Z. Yang and Q. Wang, J. Alloys Compd., 2016, 662, 118-125.

169 Q. He, Z. Zeng, Z. Yin, H. Li, S. Wu, X. Huang and H. Zhang, Small, 2012, 8, 2994-2999.

170 N. Singh, R. K. Gupta and P. S. Lee, ACS Appl. Mater. Interfaces, 2011, 3, 2246-2252.

171 T. Wei, P. Yeh, S. Lu and Z. L. Wang, J. Am. Chem. Soc., 2009, 131, 17690-17695.

172 S. Wu, Z. Zeng, Q. He, Z. Wang, S. J. Wang, Y. Du, Z. Yin, X. Sun, W. Chen and H. Zhang, Small, 2012, 8, 2264-2270.

173 L. Wang, Y. Wang, J. I. Wong, T. Palacios, J. Kong and H. Y. Yang, Small, 2014, 10, 1101-1105.

174 A. B. Farimani, K. Min and N. R. Aluru, ACS Nano, 2014, 8, 7914-7922.

175 K. Jin, L. Xie, Y. Tian and D. Liu, J. Phys. Chem. C, 2016, 120, 11204-11209.

176 S. Su, H. Sun, F. Xu, L. Yuwen, C. Fan and L. Wang, Microchim. Acta, 2014, 181, 1497-1503.

177 O. Lopez-Sanchez, D. Lembke, M. Kayci, A. Radenovic and A. Kis, Nat. Nanotechnol., 2013, 8, 497-501.

178 D. Kufer, I. Nikitskiy, T. Lasanta, G. Navickaite, F. H. Koppens and G. Konstantatos, Adv. Mater., 2015, 27, 176-180.

179 J. Miao, W. Hu, Y. Jing, W. Luo, L. Liao, A. Pan, S. Wu, J. Cheng, X. Chen and W. Lu, Small, 2015, 11, 2392-2398.

180 W. Zhang, P. Zhang, Z. Su and G. Wei, Nanoscale, 2015, 7, 18364-18378.

181 S. Mouri, Y. Miyauchi and K. Matsuda, Nano Lett., 2013, 13, 5944-5948.

182 C. Tan and H. Zhang, Chem. Soc. Rev., 2015, 44, 2713-2731. 